\title{
The "Need to Knowledge" Model: An operational framework for knowledge translation and technology transfer
}

\author{
Joseph P. Lane \\ Center on Knowledge Translation for Technology Transfer, State University of New York at Buffalo, 100 Sylvan \\ Parkway Suite, 400, Amherst, NY 14228, USA \\ Tel.: +1 7162048606 extension: 211; Fax: +1 715204 8610; E-mail: joelane@buffalo.edu
}

\begin{abstract}
Despite substantial and sustained investment of public funds in research and development, the return in new or improved Assistive Technology devices or services has not met expectations. The paper asserts that the creation, translation and transfer of technology-based knowledge is hampered by assumptions regarding the primacy of research over development and production, and the accompanying dominance of academia over industry. Parity between methods and sectors is needed to transform ideas into inventions and on to innovations. The Need to Knowledge Model offers a framework for achieving this parity in practice.
\end{abstract}

Keywords: Knowledge translation, technology transfer, research discovery, development invention, production innovation

\section{Background}

Assistive Technology (AT) devices and services support persons with a wide range of functional limitations. Society invests resources in their creation and distribution aiming to provide equal access to persons of all ages and all abilities. This paper focuses on the three key economic sectors involved in generating AT: government, academia and industry. The authors present a model for technology-based innovation containing the key methods, activities and actions required to achieve success. The following pages describe the perspective underlying the model, and the rationale for all elements described.

Collectively the three sectors implement the continuum of three distinct methods which transform technology-based knowledge across three successive states: 1) Scientific Research methods generate Conceptual Discovery; 2) Engineering Development methods generate Prototype Invention; 3) Industrial Production methods generate Commercial Innovation [11]. The kernel of knowledge in each state of knowledge is exchanged between the relevant stakeholders through three processes: 1) Knowledge Translation is a process for communicating the value of conceptual dis- coveries; 2) Technology Transfer is a means for shifting ownership and control over prototype inventions; 3) Commercial Transactions confers ownership of finished goods/services to users, in exchange for monetary compensation.

AT devices and services are intended to provide functional capabilities to end users or care providers. Successfully achieving this intent marks the culmination of a complex process involving multiple stakeholders from the three sectors. These stakeholders must collaborate to progressively transform knowledge about user's problems from conceptual ideas into knowledge embodied as technology-based solutions.

Transformation processes involve the translation of user problems into specifications for solution, and subsequently the progression of viable solutions through scientific research, engineering development and industrial production, with eventual release in the commercial marketplace. Such progression typically involves hand-offs across and between a series of intermediary stakeholders, rather than any direct exchange between researchers and end-users. There may be direct interaction with end users during the intermediate phases of activity, but that is in the context of evalua- 
tion and testing - not as a finished good/service in the marketplace.

This is an important distinction for anyone expecting to traverse the entire innovation process from laboratory to marketplace. Researchers want to view the treat end-users (e.g., people with disabilities, the elderly) as their customers. However, in doing so they overlook the essential intermediary who is the real customer for the outputs from scientific research or development, the intermediary laboratory engineers and corporate designers who must be willing to accept the conceptual discovery or prototype invention from the academic community, and integrate it within their industrial production methods.

What mechanisms enable such translation and transfer to occur? There are examples of successful solutions that resulted from the passive and indirect diffusion of knowledge from academia out to industry what is called the linear model of innovation [7]. Still other successes arose from serendipitous contact between those with knowledge about a validated problem and those with knowledge about a viable solution. However, neither of these avenues represents a systematic and deliberate approach to solving problems, nor do they offer sufficient structure to be replicable on a scale necessary to address societal limitations.

National governments around the world have invested a great deal of public funds over several decades in research and development programs, established to create deliberate and systematic approaches to the creation, testing and delivery of new or improved AT devices and services. The majority of the funding was allocated to university-based laboratories under the linear model of innovation. The assumption being that academics will advance the state of technology and publish their results, which are then - somehow and someway - taken up by private industry to create the next generation of devices and services.

However, this linear model of innovation is widely discredited in practice, because of the cultural, procedural and resource gaps between government, academic and industrial sectors [12]. The translation and transfer hand-offs between stakeholders and sectors, require both careful coordination and close orchestration. Neither is likely to occur when the parties are operating independently and sequentially [7].

The effective and efficient translation and transfer of technology-based knowledge, as a viable solution to a validated problem, requires careful consideration of two factors: 1) the absorptive capacity of the organizations involved, and 2) the absorbability of the knowl- edge in each of the three different states. Absorptive capacity is the ability of a firm to recognize the value of new, external information, assimilate it, and apply it to commercial ends. It represents the intellectual capability of the core staff [5].

Firms require some minimum level of absorptive capacity to survive in a competitive environment, so it is unlikely that knowledge recipients are a key barrier to translation and transfer of technology-based knowledge. Instead, knowledge translation literature suggests that the knowledge creator must prepare it for absorption by tailoring the language and format to the values and context of the intended recipient [13]. This effort is particularly important when the knowledge exchange is between the different cultures present in the different sectors of academia, industry and government, further amplified when the exchange involves a change in knowledge state from concept to prototype, or prototype to product.

The well intended agencies and individuals involved in these worthy efforts would benefit from a structure to guide and inform their work. Consequently, all fields depending on technology-based innovations - including AT devices and services - benefit from an operational framework capable of linking the critical activities of all the relevant stakeholders. Such an operational framework facilitates long-term planning, resource allocation and performance evaluations. These managerial tasks are often lacking in government funded research and development projects, particularly those conducted by persons whose expertise in science or engineering far exceeds their training in such managerial skills [10].

The operational framework should be grounded in evidence-based examples drawn from both research and practice literature to ensure its acceptance among the government, academic and industry partners. The evidence also helps each sector identify where their internal expertise can be applied, and identifies gaps in their collective absorptive capabilities which can be filled by external consultants when needed.

Collectively the framework's attributes can help funding agencies and their grantees achieve the highest level of societal impact from a limited pool of public resources. In this case applying technology-based R\&D to successfully generate new or improved AT devices and services.

\section{Rationale}

Many government agencies fund basic or applied research projects that are intended to generate conceptual 
discoveries - one state of knowledge. These conceptual discoveries represent novel contributions to the global base of knowledge. They are typically documented and disseminated through conference presentations or scholarly publications, with their main audience being other basic or applied researchers.

By definition, the conceptual discoveries generated through applied research are expected to be put into practice by members of some associated stakeholder group. For example, stakeholders in laboratories or individual entrepreneurs work with technology-based knowledge. They may apply development methods to transform the conceptual discoveries into tangible inventions. These inventions are proof-of-concept prototypes, demonstrating the feasibility of knowledge use as a product or service in whole or as a component. This is considered as the invention state of knowledge, because by intellectual property law definitions all inventions must demonstrate both novelty and feasibility.

One more transformation is required to create a device or service useful to society. The prototype invention must be transformed by people trained in business methods into a finished good or service that can be produced and distributed. The finished good or service represents the product innovation state of knowledge. To generate economic value to the producer as well as functional value to the consumer, the innovation's design must include material, tooling and assembly specifications that can provide the required performance, durability, reliability and safety. To achieve some economy of scale, a device is designed to be produced in mass quantities while a service is designed to be easily adopted. Collectively these attributes represent the innovation's utility The attributes of novelty and feasibility from the prior knowledge states, combined with utility from the current state, define the three value dimensions required of a technology-based innovation novelty, feasibility and utility.

All of the above inputs, processes and outputs are necessary to successfully generate a technological innovation. They are assumed to be in play when governments or other sponsors declare that new investments in "R\&D" will create useful devices and services, which in turn will generate beneficial impacts for some target population. Despite the sponsor's declared intent, if the new investments are channeled exclusively to university-based researchers, the outputs will primarily consist of conceptual discoveries. These outputs simultaneously reflect the scholar's expertise in the methods of research, and their lack of expertise in the methods of development and/or production.
Government investments in research and development for AT outcomes have repeatedly experienced such results in Europe and North America. The projects generate many presentations and publications, contribute some new content to standards and guidelines, and result in a few proof-of-concept prototypes. Unfortunately there is scant evidence of such projects contributing to finished goods or services in the commercial marketplace. Why? A longitudinal retrospective study conducted in the AT field revealed that the academic project managers are not applying standard project management tools to allocate sufficient time, resources or personnel to accomplish the post-research activities of engineering development, technology transfer and support for industrial production. Even those projects initiated with corporate partners lack sufficient management oversight to achieve the necessary hand-offs within the time and budget allocated [10] Having sponsors and grantees approach technology-based innovation programs with the full research, development and production continuum in mind, would increase the rigor and relevance of project plans, review criteria, implementation management and program evaluation.

The government sponsors and their grantees complain about a "valley of death" - the absence of additional resources to bridge the gap between their project outputs and the marketplace. They erroneously conclude that additional investment is needed above and beyond that already expended in their efforts. Scholars corrected this mischaracterization by describing a "Darwinian Sea" teeming with resources to transform discoveries into inventions and inventions into innovations [3]. It happens that the investment resources available to $R \& D$ projects within this Darwinian Sea are only available to those projects which have carefully preserved the market value of the knowledge, and have properly communicated that value to those intermediate customers who are willing to complete the transfer of the associated technology. Investigators who complain about a dearth of available funds to advance their own projects need to recognize that they have either failed to consider the investor's requirements, or failed to communicate the knowledge in a form valued by the intermediate customers.

For university-based R\&D projects, intermediate customers include the institution's office for technology transfer. To the extent the office staff fail to grasp the value of the research discovery or development prototype, they are likely to refuse to invest time in seeking a commercial partner. Even if they expend some minimal effort, their success will be constrained by their 
inability to communicate the value to others, since they won't appreciate the value themselves. For small markets like assistive technology, one may need to engage these offices at the project's onset, and identify related mainstream applications to get their interest, because their limited resources are allocated to transfer opportunities with the highest potential for future financial returns [1].

Government sponsors have two options to increase the downstream success at transforming conceptual discoveries into prototype inventions and those inventions into device and service innovations. The preferred option is for funding agencies to share the available resources with those downstream stakeholders capable of transforming knowledge into the second and third states, and to require broad collaboration and planning among all stakeholders prior to the inception of any project. This approach would increase the likelihood of meeting the requirements for investment from other sources.

If this option is ideologically or politically impossible, the funding agencies could still require the researchers to document how their own contributions fit within the broader context, and to devise plans to preserve and track the core value of the conceptual knowledge as it progresses through the development and production transformations necessary to yield utility for the intended beneficiaries. This approach might not guarantee survival in the Darwinian Sea, but it would at least increase the odds of success against the competition.

The following framework is designed to support all of the stakeholders involved in either option. The framework includes the elements necessary to translate knowledge from producers to consumers, and to transfer ownership and control between the stakeholders with expertise in each phase of activity.

\section{3. "Need to Knowledge" Model}

Knowledge Translation is the most recent in a succession of approaches to efficiently summarizing and effectively communicating research-based knowledge to stakeholders who are positioned to implement it. The Knowledge to Action model is widely cited as a fair and comprehensive representation of this approach [8].

As explained above, technology-based knowledge intended to generate devices or services, involves three methodologies that output knowledge in three distinct states. An appropriate Knowledge Translation model needs to consider how to communicate knowledge in all three states. For devices and services expected to benefit society, the model should begin with an identified problem and end with a validated technology-based solution to that problem.

The "Need to Knowledge" is an expansion of the KTA model. While the KTA Model assumes a requirement for generating new knowledge through research activity, the Need to Knowledge (NtK) Model adds stages to the front end, and articulates steps within the research, development and production phases. These steps were drawn from best practices recommended by the Product Development \& Management Association [9]. Prior to considering any research activity, the NtK Model requires the participants to articulate a validated problem and present a potential solution. To the extent the solution to a defined need requires the generation of new knowledge, a stage/gate framework permits the application of any or all of the three phases of research, development and production activity to generate the needed new knowledge in its appropriate state [11].

The NtK model begins by articulating a problem amenable to a technology-based solution, then determines what knowledge is needed to progress from problem to solution - need to knowledge. The application of research, development or production methods is contingent on the requirements of the defined project. If the needed conceptual discoveries already exist in published literature and patents, there may be no need for conducting further research, so the project can proceed directly to development activity. If not, research methods may first be necessary to generate the needed conceptual discoveries. In either case, development may be required to generate proof of concept prototypes, or existing prototypes may require refinement for this envisioned application. If all necessary research and development is already completed by some stakeholders somewhere, the project may bypass any further R\&D activity, and instead move directly into the production phase.

The "Need to Knowledge" model reduces a very complex process of translation and transfer to three basic Phases and nine Stages - three Stages per Phase (see Fig. 1). Every Stage contains a nested set of Steps, along with Tips for completing the Steps.

Not shown in Fig. 1 yet equally critical is the presence of "Decision Gates" at the completion of each Stage - nine Decision Gates in all. These Decision Gates are critical because many projects take on a life of their own, heedless of the likelihood of actually ac- 


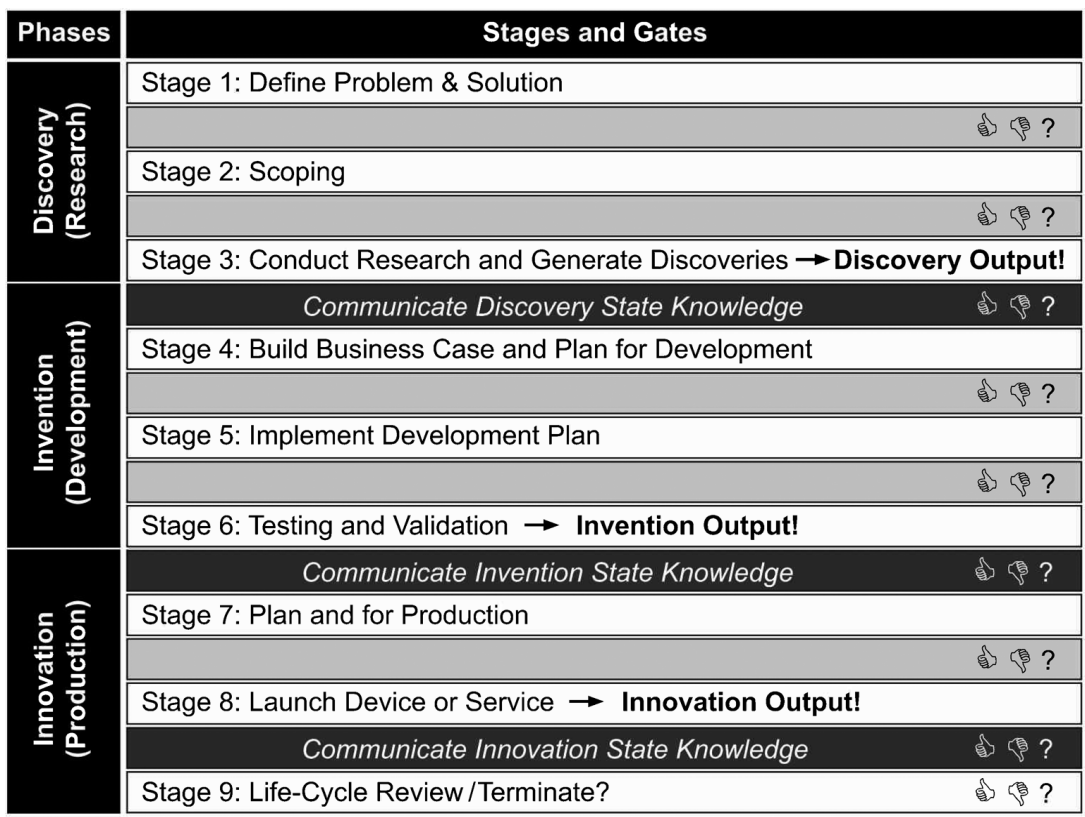

Fig. 1. Outline of Need to Knowledge Model. (Colours are visible in the online version of the article; http://dx.doi.org/10.3233/TAD-2012-0346)

complishing the original goal. Decision Gates permit participants to question the wisdom of initiating the next Stage of activity, and doing so with the actual results of the prior Stage in hand. The decision to continue or stop should depend on the likelihood of reaching the goal, rather than on inadequate funds or time to continue due to insufficient planning and resource management.

All elements of the NtK Model are supported by findings or claims extracted from a scoping review of hundreds of articles appearing in academic or industry literature. These primary sources also yielded many secondary references to additional publications. The supporting literature is accessible to model users who may wish to explore that material in greater detail. An article describing the model is in preparation, while the full "Need to Knowledge" model is freely available for public access and use on the web at: http://kt4tt.buffalo. edu/knowledgebase/model.php.

At the culmination of each phase of research, development and production, the "Need to Knowledge" model contains diagrams for conducting Knowledge Translation. The diagrams adapt the "Knowledge to Action" model to more accurately represent the communication steps required for each state of knowledge. They include tables showing how to tailor knowledge to six different stakeholder groups: researchers; clinicians; manufacturers; consumers; brokers; policy makers [11].

\section{Implications for policy and practice}

Governments attempting to stimulate technology transfer need to shift existing policies from the passive linear model of innovation, to the active and open collaborative model, where science and technology "R\&D" are directly linked to - and designed in support of - industrial production of new or improved devices and services.

The Need to Knowledge (NtK) model reaffirms that the commercialization process is quite complex. No organization, investigator or project can be held singularly responsible for completing the entire process However, they should be held accountable for productively contributing within an open and dynamic environment for innovation.

According to Dr. Michael Gibbons [6]:

'The once clear lines of demarcation between government, industry, and the universities, between science of the university and the technology of industry, between basic research, applied research, and product development, between careers in academe and those in industry no longer apply'

Policy makers are beginning to embrace the concept of open innovation which permits governments to facilitate internal and external knowledge flows, and to support knowledge exchanges between any source and their various stakeholders [4]. Companies are also ex- 
ploring collaborative or challenge-led models of innovation, where the project requirements drive the partnerships, rather than having core capabilities limit the project options.

In all cases, persons intended to contribute to technology-based projects need to clearly comprehend the overall goal, define their own role and appreciate those of others, know their customer and the target market, and define research and development capabilities as opportunities to add value to a corporate partner's core competencies [2].

Integrating research activity within a broader societal framework of dynamic problem solving helps ensure both rigor and relevance, while helping industry fulfill a critical role in transforming discoveries into inventions, and then on to innovations for the marketplace. This is the key to achieving beneficial societal impacts from the investment of public funds.

\section{Acknowledgements}

This is a publication of the Center on Knowledge Translation for Technology Transfer, which is funded by the National Institute on Disability and Rehabilitation Research of the U.S. Department of Education under grant number H133A080050. The opinions contained in this presentation are those of the grantee and do not necessarily reflect those of the U.S. Department of Education.

\section{References}

[1] S.M. Bauer and J.A. Flagg, Technology Transfer and Intermediaries. Assistive Technology Outcomes and Benefits, 2010, pp. 129-150, http://www.atia.org/files/public/ATOBV6N1Ar ticleSix.pdf.
[2] S.M. Bauer and JP Lane, Convergence of assistive devices and mainstream products, Technology \& Disability 18(2) (2006), 67-78.

[3] L. Brancomb and P. Auerswald, Taking Technical Risks: How innovators, manager and investors manage risk in high tech innovations, MIT Press, 2001.

[4] H. Chesbrough, Open Innovation: The New Imperative for Creating and Profiting from Technology, Boston, Harvard University Press, 2003.

[5] W.M. Cohen and D.A. Levinthal, Absorptive Capacity: A new perspective on learning and innovation, $A S Q, 35$, (1990), $128-152$.

[6] M. Gibbons, Why is knowledge translation important? Grounding the conversation, Focus Technical Brief, 21, (2008) $1-9$.

[7] B. Godin, The Linear Model of Innovation: The historical construction of an analytic framework, Science, Technology \& Human Values 31(6) (2006), 639-667.

[8] I.D. Graham, J. Logan, M.B. Harrison, S.E. Straus, J. Tetroe, R.N. Caswell and N. Robinson, Lost in Knowledge Translation: Time for a Map, The Journal of Continuing Education in the Health Professions, 26, (2006), 13-24. http://www.jcehp. com/vol26/2601 graham2006.pdf.

[9] K.B. Kahn, PDMA Handbook of New Product Development (2nd Edition). John Wiley \& Sons (2005).

[10] J.P. Lane, Delivering on the 'D' in R\&D: Recommendations for increasing transfer outcomes from development projects", Assistive Technology Outcomes and Benefits, Special Issue Fall, 2008.

[11] J.P. Lane and J.L. Flagg, Translating three states of knowledge: discovery, invention, innovation Implementation Science, (2010), 5/9 http://www.implementationscience.com/content/5 $/ 1 / 9$.

[12] D. Sarewitz, Frontiers of Illusion: Science, technology and the politics of progress. Philadelphia, Temple University Press, 1996.

[13] A.M. Sherwood and R.P. Melia, Knowledge translation: A mandate for Federal research agencies, Journal of Rehabilitation Research and Development 44 (2007), vii-x.

[14] P. Sudsuwad, Knowledge Translation: Introduction to models, strategies and measures, Austin, TX: Southwest Educational Development Laboratory, National Center for the Dissemination of Disability Research, 2007. 